\title{
Even Intense Religiosity Is Declining in the United States
}

\author{
David Voas, ${ }^{\mathrm{a}}$ Mark Chaves ${ }^{\mathrm{b}}$
}

a) University College London; b) Duke University

Abstract: In their 2017 article, "The Persistent and Exceptional Intensity of American Religion: A Response to Recent Research," Schnabel and Bock claimed that "intense religion ... is persistent and, in fact, only moderate religion is on the decline in the United States." In this article, we show that even the intensely religious segment of the American population is indeed shrinking. Schnabel and Bock mistakenly concluded otherwise because their analytical strategy was not sufficiently sensitive to detect very slow change (leading them to miss signs of declining intense religion on the indicators they examined), they examined a limited set of indicators (missing still more signs of declining intense religion), and they paid insufficient attention to cohort differences. Overall, their empirical conclusion that "only moderate religion is on the decline in the United States" is simply false. And their interpretive conclusion that "intense religion in the United States is persistent and exceptional in ways that do not fit the secularization thesis" should be rejected.

Keywords: religion; religiosity; religious trends; secularization; American exceptionalism

Citation: Voas, David, and Mark Chaves. 2018. "Even Intense Religiosity Is Declining in the United States." Sociological Science 5: 694-710.

Received: August 3, 2018

Accepted: September 30, 2018

Published: November 15, 2018

Editor(s): Jesper Sørensen, Stephen Morgan

DOI: $10.15195 /$ v5.a29

Copyright: (C) 2018 The Author(s). This open-access article has been published under a $\mathrm{Cre}$ ative Commons Attribution License, which allows unrestricted use, distribution and reproduction, in any form, as long as the original author and source have been credited. (C) (i)
$\mathbf{T}^{\mathrm{N}}$ an article published in 2016 in the American Journal of Sociology (AJS), we asked 1 whether the United States is a counterexample to the secularization thesis (i.e., the idea that modernization tends to undermine religious belief and activity). We provided evidence that it is not. Acknowledging the obvious fact that American levels of religious involvement remain strikingly high compared to those in virtually all highly developed countries, we claimed that:

"[F]or two straightforward empirical reasons, the United States should no longer be considered a counterexample [to the secularization thesis]. First, it has recently become clear that American religiosity has been declining for decades. Second, this decline has been produced by the generational patterns underlying religious decline elsewhere in the West: Each successive cohort is less religious than the preceding one. America is not an exception" (Voas and Chaves 2016:1517-18).

In their 2017 Sociological Science article, Schnabel and Bock offered an alternative view, claiming that "intense religion . . is persistent and, in fact, only moderate religion is on the decline in the United States" (2017:686). Because intense religiosity is declining elsewhere in the developed world, they concluded that "intense religion in the United States is persistent and exceptional in ways that do not fit the secularization thesis." Schnabel and Bock agreed with us that, on average, American religiosity is declining, but they claimed that the share of the American population that is highly religious has not declined even if the rest of the population is becoming more secular, and for that reason, the United States remains exceptional. They 
did not address the second central point of our original article: Aggregate religious decline in the United States is produced largely by generational replacement.

In this article, we show that even the intensely religious segment of the American population is shrinking. Schnabel and Bock mistakenly concluded otherwise because they missed signs of declining intense religion on the indicators they examined, they examined a limited set of indicators (missing still more signs of declining intense religion), and they paid insufficient attention to cohort differences. Overall, their empirical conclusion that "only moderate religion is on the decline in the United States" (2017:686) is simply false. And their interpretive conclusion that "intense religion in the United States is persistent and exceptional in ways that do not fit the secularization thesis" (2017:686) should be rejected.

\section{Signs of Decline in Intense Religiosity Even on the Schnabel and Bock Indicators}

A major challenge for examining religious trends in the United States is that religious change in the West is largely generational, as shown by a growing body of evidence (for example, Hout and Fischer 2014; Kregting et al. 2018; Molteni and Biolcati 2018; Ruck, Bentley, and Lawson 2018), and generational change usually is very slow. It is hard to spot over short periods with conventional survey data; even a couple of decades may not be enough. We pointed out in our 2016 article that it is only now (45 years after the creation of the General Social Survey [GSS]) that the evidence for decline is completely compelling. Schnabel and Bock missed clear signs of declining intense religion even on the indicators they examined in part because they focused only on the period since the late 1980s and in part because they did not look hard enough for slow change. Year-to-year sampling error makes slow, long-term change harder to spot, but the signal is there.

Schnabel and Bock examined five indicators of intense religion: strong religious affiliation, attending religious services multiple times per week, biblical literalism, affiliation with an evangelical religious group, and praying multiple times per day. Panel A of Table 1 provides basic information about these items. Schnabel and Bock asserted that all of these indicators display persistence, but this is incorrect. Three of these five indicators of intense religion - affiliation, attendance, and literalismshow clear signs of decline.

Figure 1 essentially reproduces the same intense religiosity trends for these five items that were presented in Figures 1-5 in Schnabel and Bock's article. We have not exactly reproduced their trend lines because although we all are using appropriately weighted General Social Survey data, we begin observing in 1973 rather than the late 1980s, and we limit analysis to the native-born population who were 20 to 84 years old at the time they were interviewed. We limit analysis to the native-born population so that we are comparing religious trends within a population that is comparable across the observation period rather than comparing the "apples" of a population that contains fewer immigrants earlier in the period to the "oranges" of a population that contains more immigrants later in the period. Results are substantively the same regardless of whether the analysis is limited 
Table 1: Indicators of intense religiosity from the General Social Survey.

\begin{tabular}{|c|c|c|c|}
\hline Variable name & Indicator & Mean \% 2006-2016 & Survey years \\
\hline \multicolumn{4}{|c|}{ Panel A: Schnabel and Bock Items } \\
\hline Reliten & Calls self a strong [religious preference] & 36.3 & 29 from 1974-2016 \\
\hline Attend & Attends religious services several times per week & 7.0 & 31 from $1972-2016$ \\
\hline Bible & $\begin{array}{l}\text { "The Bible is the actual word of God and is to be taken } \\
\text { literally, word for word" }\end{array}$ & 31.4 & 20 from 1984-2016 \\
\hline Reltrad $^{\mathrm{a}}$ & Identifies with a denomination classified as evangelical & 29.5 & 31 from $1972-2016$ \\
\hline Pray & Prays several times per day & 29.1 & 20 from 1983-2016 \\
\hline \multicolumn{4}{|c|}{ Panel B: Additional Items } \\
\hline God & "I know God really exists and I have no doubts about it" & 58.4 & 12 from $1988-2016$ \\
\hline Relpersn & Considers self a very religious person & 17.9 & 7 from 1998-2016 \\
\hline Punsin & $\begin{array}{l}\text { Agrees strongly that "those who violate God's rules must } \\
\text { be punished" }\end{array}$ & 14.7 & 4 from $1988-2010$ \\
\hline Godmeans & $\begin{array}{l}\text { Strongly agrees that "to me, life is meaningful only be- } \\
\text { cause God exists" }\end{array}$ & 19.1 & 3 from 1991-2008 \\
\hline Rellife & $\begin{array}{l}\text { Strongly agrees that "I try hard to carry my religious } \\
\text { beliefs over into all my other dealings in life" }\end{array}$ & 28.7 & 4 from $1998-2010$ \\
\hline
\end{tabular}

${ }^{\text {a }}$ Reltrad is not a GSS variable. It is constructed from GSS items asking about respondents' religious affiliation using an adapted and updated version of the variable developed in Steensland et al. (2000).

to the native-born population. ${ }^{1}$ We do not understand why Schnabel and Bock examined the trends beginning only in the late 1980s, and we believe it is better to use as much of the available data as we can. ${ }^{2}$

Notwithstanding the small differences between how we and they calculated trend lines, our lines look qualitatively similar to Schnabel and Bock's: There is no large decline over this period on any of these indicators. But this is because decline is slow and there is year-to-year sampling error fluctuation, not because there is no decline.

Panel A of Table 2 shows the results when each of the five indicators used by Schnabel and Bock is regressed on year. These results make clear that three of these five lines-for strong affiliation, attending multiple times per week, and believing that the Bible is the literal word of God-slope significantly downward. The slopes for evangelical affiliation and frequent prayer are significantly positive if viewed over the whole period since the questions were first asked, but there are complexities regarding these two trends that are worth mentioning.

It is well known that a straight line is not the best representation of membership trends in evangelical denominations in recent decades. The evangelical share rose through the 1980s and has slowly declined since then (Putnam and Campbell 2010:104-5; Chaves 2017:93-99). When we regress year on evangelical affiliation only since 1989, the slope is significantly negative, as reported in Table 2 . Taking a step back, we do not think belonging to an evangelical denomination is a valid indicator of intense religiosity. There is substantial variation in religious intensity across individuals in both evangelical and nonevangelical denominations, and we have direct indicators of religious practice and belief, so we do not think that the trend in evangelical affiliation is relevant for an assessment of intense religiosity. 


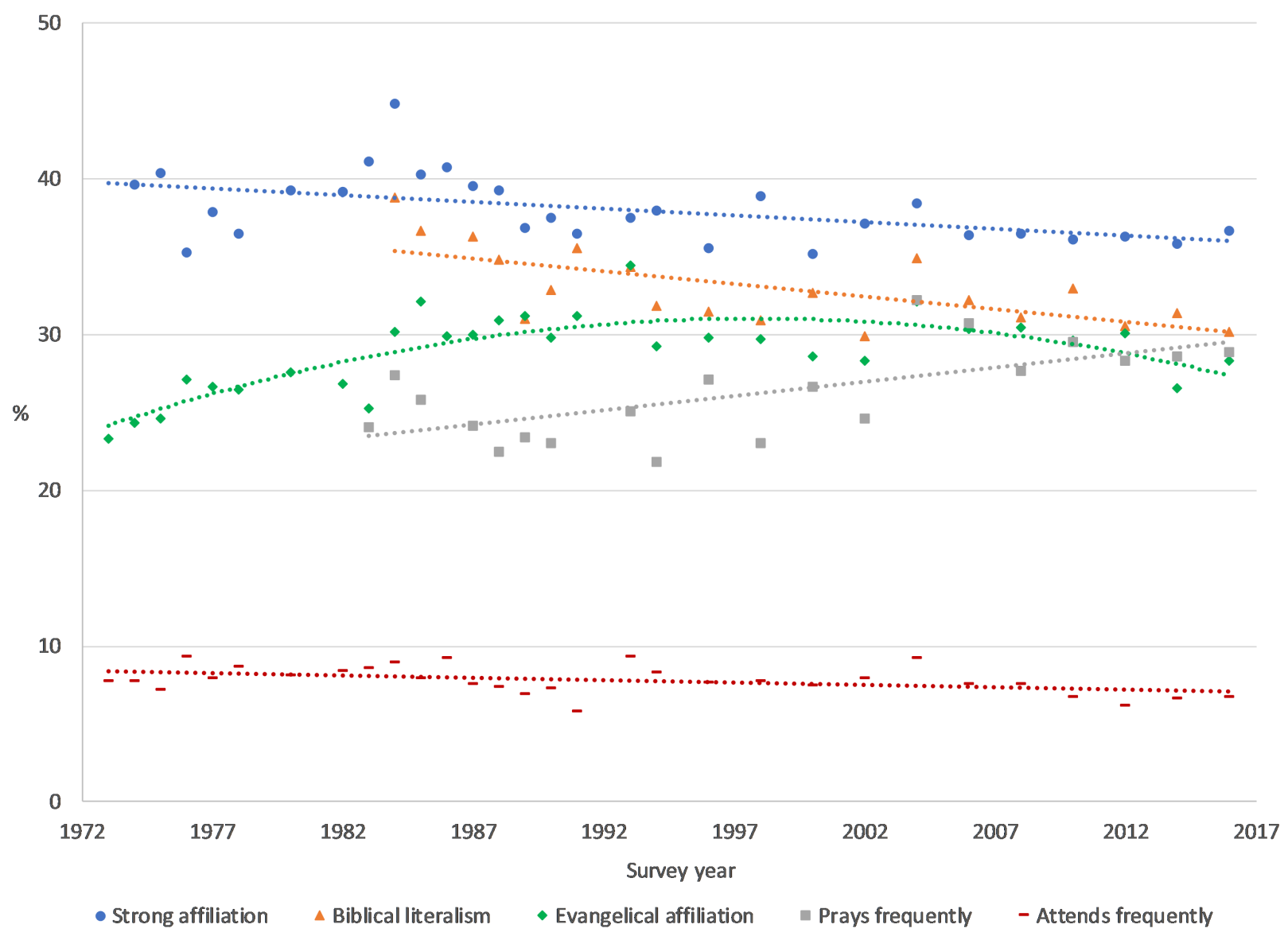

Figure 1: Intense religiosity by survey year (items used by Schnabel and Bock). Source: General Social Survey, 1973-2016.

But we retain it here because Schnabel and Bock used it, and we note that it, too, has declined since 1989.

Regarding frequent prayer, there is an intriguing discontinuity in the GSS data between 2002 and 2004. Between 1983 and 2002, there is essentially no change in the percentage of those saying that they pray several times per day, but the value jumps dramatically from 24.6 percent in 2002 to 32.2 percent in the next GSS survey in 2004, and it declines thereafter. The later values are all higher than the earlier values, so a trend line across the whole series has a positive slope, as shown in Table 2. Looking at the segments separately, however, there was no change for the first two decades and then a gradual decline (from a higher starting point) in the later period.

It is not clear why the proportion of those reporting very frequent prayer jumped dramatically between 2002 and 2004. The GSS made several methodological changes in 2004. It was the first time that the GSS used a new sampling frame based on the 2000 census and the first year that the GSS subsampled respondents to use data collection resources more efficiently. A code for "never" was added to the prayer 
Table 2: Logistic regression of intense religiosity indicator on survey year.

\begin{tabular}{|c|c|c|}
\hline Variable name & Indicator & $\begin{array}{c}\text { B } \\
\text { (standard error) }\end{array}$ \\
\hline \multicolumn{3}{|c|}{ Panel A: Schnabel and Bock Items } \\
\hline Reliten & Calls self a strong [religious preference] & $\begin{array}{r}-0.004^{\dagger} \\
(0.001)\end{array}$ \\
\hline Attend & Attends religious services several times per week & $\begin{array}{r}-0.004^{\dagger} \\
(0.001)\end{array}$ \\
\hline Bible & "The Bible is the actual word of God and is to be taken literally, word for word" & $\begin{array}{r}-0.006^{\dagger} \\
(0.001)\end{array}$ \\
\hline Reltrad & Identifies with a denomination classified as evangelical (all available survey years) & $\begin{array}{c}0.004^{\dagger} \\
(0.001)\end{array}$ \\
\hline Reltrad & Identifies with a denomination classified as evangelical (survey years since 1989) & $\begin{array}{r}-0.004^{\dagger} \\
(0.001)\end{array}$ \\
\hline Pray & Prays several times per day (all available survey years) & $\begin{array}{r}0.009^{\dagger} \\
(0.001)\end{array}$ \\
\hline Pray & Prays several times per day (survey years since 2004) & $\begin{array}{r}-0.010^{*} \\
(0.005)\end{array}$ \\
\hline God & $\begin{array}{l}\text { Panel B: Additional Items } \\
\text { "I know God really exists and I have no doubts about it" }\end{array}$ & $\begin{array}{r}-0.014^{\dagger} \\
(0.002)\end{array}$ \\
\hline Relpersn & Considers self a very religious person & $\begin{array}{r}-0.008 \\
(0.004)\end{array}$ \\
\hline Punsin & Agrees strongly that "those who violate God's rules must be punished" & $\begin{array}{r}-0.028^{\dagger} \\
(0.004)\end{array}$ \\
\hline Godmeans & Strongly agrees that "to me, life is meaningful only because God exists" & $\begin{array}{r}-0.013^{*} \\
(0.006)\end{array}$ \\
\hline Rellife & $\begin{array}{l}\text { Strongly agrees that "I try hard to carry my religious beliefs over into all my other } \\
\text { dealings in life" }\end{array}$ & $\begin{array}{c}0.012 \\
(0.007)\end{array}$ \\
\hline
\end{tabular}

${ }^{*} p<0.05,{ }^{+} p<0.01$

item, though interviewers were instructed not to offer it as an option in probing for an answer. There also is a question-order difference in the 2004 through 2016 surveys compared to the earlier surveys that could have had an effect. ${ }^{3}$ These changes seem unlikely to have produced a jump of this magnitude, but it would be interesting to investigate the cause of this discontinuity. We leave that for future research. For now, frequent prayer appears to be an exception to the general pattern of decline in intense religiosity, although the dramatic jump in 2004 raises questions, and even this item shows decline since 2004. ${ }^{4}$

Panel A of Table 3 shows the percentage point differences on the most "intense" response to these five items when the 2010 through 2016 surveys are aggregated and compared to surveys aggregated over a similar time span at the beginning of the data series for each item. The picture is clear and consistent with the regression results in Table 2. Three of the five indicators show a clear decline in the proportion of people who give the most intensely religious response. In 1974 through 1980, 38.1 percent reported a strong affiliation with a religious group, which declined to 36.2 percent in 2010 through 2016. Attending religious services more than once per week also declined from 8.1 percent in 1973 through 1978 to 6.6 percent in 2010 
Table 3: Intense religiosity indicators for pooled survey years (\%).

\begin{tabular}{|c|c|c|c|}
\hline Variable name & Indicator & Earlier Period $^{\mathrm{a}}$ & $2010-2016^{b}$ \\
\hline \multicolumn{4}{|c|}{ Panel A: Schnabel and Bock Items } \\
\hline Reliten & Calls self a strong [religious preference] & 38.1 & 36.2 \\
\hline Attend & Attends religious services more than weekly & 8.1 & 6.6 \\
\hline Bible & $\begin{array}{l}\text { "The Bible is the actual word of God and is to be taken literally, word } \\
\text { for word" }\end{array}$ & 35.0 & 31.2 \\
\hline Reltrad & $\begin{array}{l}\text { Identifies with a denomination classified as evangelical (all available } \\
\text { survey years) }\end{array}$ & 25.4 & 28.7 \\
\hline Pray & Prays several times per day (all available survey years) & 24.6 & 28.8 \\
\hline \multicolumn{4}{|c|}{ Panel B: Additional Items } \\
\hline God & "I know God really exists and I have no doubts about it" & 64.4 & 56.9 \\
\hline Relpersn & Considers self a very religious person & 19.1 & 17.2 \\
\hline
\end{tabular}

a The earlier period pools a set of surveys beginning when the data series for each item begins. The earlier period varies by item depending on the timing of GSS surveys and the years in which items were asked: Reliten (1974-1980), Attend (1973-1978), Bible (1984-1990), Reltrad (1973-1978), Pray (1983-1989), God (1988-1994), and Relpersn (1998-2006).

${ }^{\mathrm{b}}$ All differences are significant at $\mathrm{p}<0.01$ in two-sample $\mathrm{t}$-tests except for Relpersn, for which $\mathrm{p}=0.02$.

through 2016. ${ }^{5}$ And 35.0 percent said that the Bible is literally true in 1984 through 1990, dropping to 31.2 percent in 2010 through 2016. These differences are small, but all of them are statistically significant. As noted earlier, the evangelical share of the population increased from the 1970s to today, as did the percentage of people saying that they pray several times per day. ${ }^{6}$

In sum, it is clear that intense religiosity declined in recent decades on three of the indicators used by Schnabel and Bock. None of this decline in intense religiosity is large. On the contrary, it is quite slow. But slow decline is still decline. And even the two indicators that do not decline over this entire period-evangelical affiliation and praying frequently-have declined in the most recent decades.

It is easy to understand why Schnabel and Bock missed the evidence of decline in these measures. They examined a shorter time period, and they focused on single-survey point comparisons at the beginning and end of the period rather than increasing statistical power by combining adjacent surveys early and late in the period. These analytical decisions led them to reach the incorrect conclusion that there was no evidence of decline in intense religiosity in the items they examined.

\section{Signs of Decline on Other Indicators of Intense Religiosity}

The evidence for decline in intense religiosity is strengthened further by examining indicators beyond those examined by Schnabel and Bock. There are at least five additional indicators of intense religiosity in the GSS:

Chooses "I know God really exists and I have no doubts about it" when asked which statement comes closest to expressing one's belief about God. $^{7}$

Says "very religious" when asked, "To what extent do you consider yourself a religious person?" 


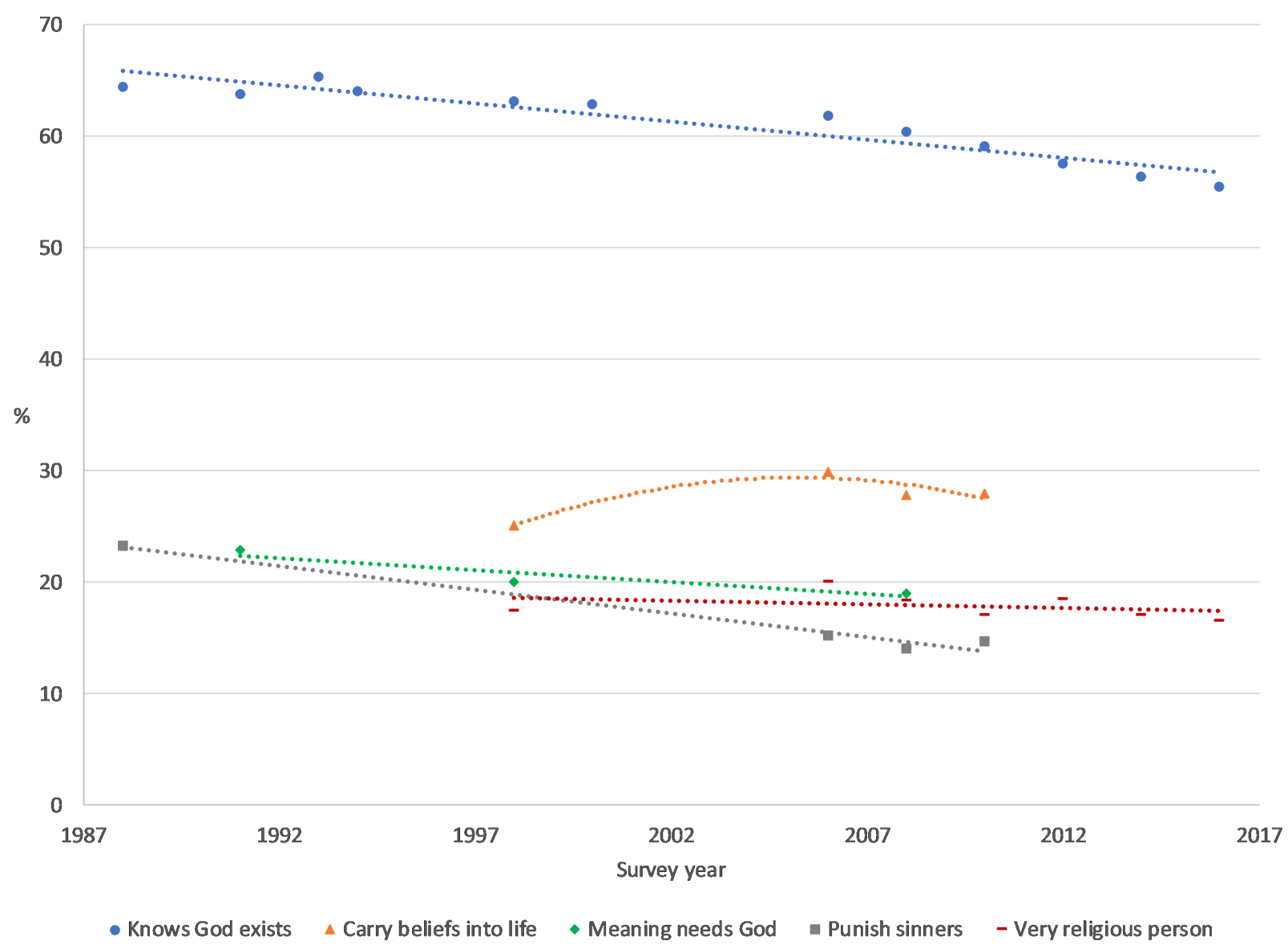

Figure 2: Intense religiosity by survey year (additional items). Source: General Social Survey, 1988-2016.

Strongly agrees that "those who violate God's rules must be punished."

Strongly agrees with the statement, "To me, life is meaningful only because God exists."

Strongly agrees with the statement, "I try hard to carry my religious beliefs over into all my other dealings in life."

Panel B of Table 1 provides additional information about these items.

The signs of decline in intense religiosity are as clear in this set of items as they are in the set of items examined by Schnabel and Bock. Figure 2 shows the downward trend in most of the indicators. Panel B of Table 2 gives the results of regressing each indicator of intense religiosity on year, and Panel B of Table 3 compares a pooled set of surveys from earlier and later periods for the two items that were included often enough on the GSS to permit sensible pooling at the two time periods.

The picture, again, is clear. The trend lines, regression coefficients, and pooled comparisons display an unambiguous picture of decline for four of the five items. In 1988 through 1994, 64.4 percent of people said that they know God exists, declining 
to 56.9 percent in 2010 through 2016 . The negative regression line slope for calling oneself a very religious person does not quite reach statistical significance at the 0.05 level, but the decline is evident in the comparison of pooled surveys: In 1998 through 2006, 19.1 percent said they were very religious, dropping to 17.2 percent in 2010 through $2016 .{ }^{8}$ Nearly one-quarter (23.1 percent) of respondents in 1988 strongly agreed that "those who violate God's rules must be punished." Only 14.7 percent did so in 2006 through 2010. ${ }^{9}$ The "life is meaningful only because God exists" question has been asked only three times (in 1991, 1998, and 2008), but strong agreement has steadily declined (from 22.9 to 20.1 to 19.0 percent, respectively). Only the proportion of those who strongly agree with the statement, "I try hard to carry my religious beliefs over into all my other dealings in life" has increased, and from just a single survey year. The percentage rose from 25.1 in 1998, when it was first asked, to 28.7 in 2006 through $2010 .{ }^{10}$ All of these differences, again, are statistically significant.

Moving beyond aggregate trends in the most religious response on single items yields still more evidence pointing to a decline in intense religiosity. For example, the 1991, 1998, and 2008 surveys asked respondents how frequently their parents attended religious services and also how frequently the respondent attended when he or she was around 12 years old. Because there are significant gender differences in religious service attendance, it is best to compare respondents' current attendance with the attendance of their same-sex parent (i.e., compare women with their mothers and men with their fathers). Among female respondents on these three surveys (pooled), 8.1 percent said they currently attend several times per week, but 11.7 percent said their mothers did the same. Among male respondents, 6.0 percent said they attend several times per week, but 6.7 percent said their fathers did the same. And overall, 11.6 percent of respondents said that they attended several times per week at age 12 , but only 6.9 percent do so now. These comparisons again point to a decline in the intensely religious population.

Another approach, one that may be better than looking at extreme values of individual items, is to operationalize intense religiosity as reporting high values simultaneously on several different indicators. Given the constraints imposed by the years in which the GSS asked various questions, and in light of our skepticism concerning affiliation with an evangelical denomination as a valid measure of intense religiosity, the best measure of this sort that we can construct combines people who strongly identify with a religious group, report attending religious services weekly or more, and say that they know without doubt that God exists. ${ }^{11}$ By now, it should come as no surprise that intense religiosity has declined by this measure as well. Comparing surveys pooled from early in the period in which this measure can be constructed with the most recent surveys, 19.8 percent of people were intensely religious by this measure in 1988 through 1994, declining to 18.3 percent in 2010 through 2016. As before, the decline is slow, but it is statistically significant. Slow decline is still decline.

Overall, intense religiosity clearly has declined in recent decades in the United States. Operationalized as choosing the most religious response option on an individual item, decline is evident on seven of the nine items available in the GSS (not including evangelical affiliation, which at best is a measure of a different 
sort). Decline is also evident when comparing respondents' reports of their current religiosity to their reports of their parents' religiosity and to their reports of their own religiosity when they were children. And it is evident when using a measure that combines high responses on several religiosity questions. The decline in intense religion is slow, to be sure, but it has occurred nonetheless.

\section{Signs of Decline in Cohort Differences in Intense Religiosity}

We have so far followed Schnabel and Bock in examining aggregate trends over time in intense religiosity, and we have shown that contrary to their conclusion, intense religiosity has declined in recent decades in the United States. But the evidence for decline is even clearer when we focus on cohort differences, as we did in our AJS article, rather than on year-to-year aggregate differences.

The five indicators used by Schnabel and Bock all show clear signs of intergenerational decline in recent years, as shown in Table 4, which uses the pooled 2010 to 2016 surveys to compare levels of intense religiosity among people born before 1945 and since 1975. People born before the end of World War II are far more likely than those born since 1975 to feel a strong sense of religious affiliation, attend services and pray very frequently, and believe that the Bible is the literal word of God. They are somewhat more likely to belong to an evangelical denomination. All of these differences are statistically significant. Such differences between the young and the old might arise if people become much more religious as they get older, but there is scant evidence of such individual-level change. ${ }^{12}$ As we showed in our AJS article, religious decline is largely the result of more-religious older generations being replaced by less-religious younger generations, whereas within-cohort change is much less substantial. In particular, we showed that within-cohort effects on affiliation are very minor, ${ }^{13}$ and focusing on strong affiliation (as opposed to strong or somewhat strong affiliation, as we did in our original article) does not change this. Attendance at services and belief in God are even less subject to within-cohort change.

Figure 3 uses the 1973 through 2016 GSS surveys to provide a more detailed look at cohort differences in intense religiosity for the 10 items listed in Table 1 (the five examined by Schnabel and Bock plus the five additional items available in the GSS). If only moderate religion is on the decline in the United States, as Schnabel and Bock claim, then the levels of intense religiosity should be approximately the same in every generation unless people become substantially more religious with age than is plausible. In fact, the highly religious share declines from one cohort to the next for every one of the 10 measures. And, apart from affiliation with an evangelical denomination, the trend lines all have similar slopes, suggesting that all of these indicators (with one exception) are measuring a common underlying trait that is declining in frequency in the population. The exception is evangelical affiliation, which has a flatter line. Only the youngest cohort is markedly lower than the others. This different pattern supports our sense that evangelical affiliation is not a valid indicator of intense religiosity and does not belong in this set of items. 
Table 4: Generation gaps in intense religiosity, 2010-2016 (\%).

\begin{tabular}{lcc}
\hline & Old & Young \\
\hline Strong affiliation & 49.0 & 27.8 \\
Attends services frequently & 10.5 & 4.2 \\
Biblical literalist & 39.3 & 25.2 \\
Evangelical affiliation & 30.6 & 26.0 \\
Prays frequently & 36.3 & 21.6 \\
\hline
\end{tabular}

Old = born before 1945 (but aged $<85$ years). Young = born 1975-1994 (but aged $\geq 20$ years).

Figure 3 is, of course, an oversimplified way to examine cohort differences because it conflates cohort change with the possibility that people in every cohort become more religious as they age. To sort that out, we need to examine results for each cohort as it ages across the survey years. ${ }^{14}$ We did this in our AJS article for the response, "I know God really exists and I have no doubts about it," and we found clear cohort differences with little sign of individual change with age or over time. ${ }^{15}$ It would be tiresome to present and describe such graphs for each of the 10 indicators of intense religiosity, but we have examined all of these graphs and found the same pattern in eight of them: Each successive birth cohort is less intensely religious than the one before, and there is little sign of people becoming more intensely religious with age or over time. ${ }^{16}$

To illustrate the typical pattern, we show the results for two variables: biblical literalism and self-description as very religious. Figure 4 highlights the decline from one generation to the next in the proportion of the population identifying the statement, "The Bible is the actual word of God and is to be taken literally, word for word," as the one that comes closest to describing how they feel about the Bible. Across all GSS surveys, 40 percent of the respondents born prior to 1935 endorse this statement; among the respondents born since 1985, less than one-quarter (23.6 percent) do so. The question was first included in the GSS in 1984, and there is little sign of within-cohort change in the more than three decades since that time. Aggregate decline is occurring because more intensely religious cohorts are gradually being replaced in the population by younger ones that are less religious. ${ }^{17}$

Figure 5 shows the percentage of respondents who describe themselves as "very religious" by decade of birth and survey year, using all the GSS surveys in which this question was asked (1998 and 2006 through 2016). Among the respondents born before World War II (in the years 1925-1944), one in four say that they are very religious. Among the respondents born since 1985, only one in 10 say the same. The lines (which represent each cohort aging over this 18-year period) are relatively flat, suggesting that there is little within-cohort change over time. The 1935 to 1944 cohort jumps from 17.2 percent to 25.6 percent between 1998 and 2006, after which it shows trendless fluctuation. The increase might be explained by boosted religiosity in retirement or even by differential mortality (with religiously active people living longer than others ${ }^{18}$ ), but it is probably just the consequence of an especially low reading in $1998(\mathrm{~N}=151)$. 
80

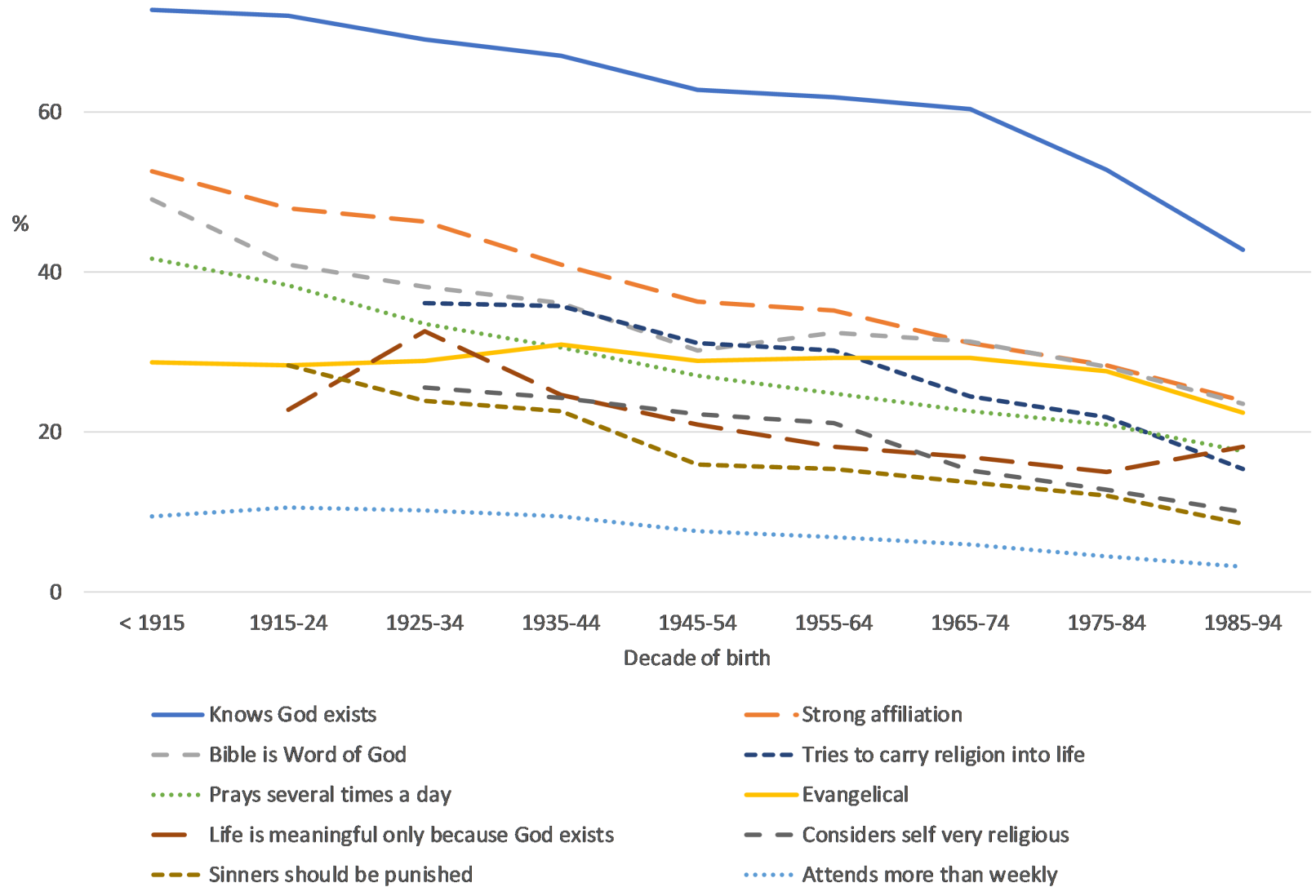

Figure 3: Highly religious share by decade of birth. Source: General Social Survey 1973-2016, pooled.

At any rate, with some noise, eight of the 10 graphs look essentially like the two just described, strongly implying that cohort replacement is driving a decline in intense religiosity just as it is driving a decline in religiosity in general. Older, more religious generations are slowly but surely being replaced by less religious people born more recently.

As described earlier, we created a combined measure of intense religiosity based on strong affiliation, weekly attendance at services, and belief in God with no doubts. The generational contrasts on this measure are striking. The 2010 through 2016 surveys give us data on people born in the decade from 1925 to 1934 and also young adults born between 1985 and 1994 (i.e., on older Americans and their grandchildren). Among the older generation, nearly one-third (32.5 percent) qualify as highly religious; only one in 10 (9.8 percent) of the young do so.

The cohort graphs that show a different pattern are for the two items already discussed: praying several times per day and affiliation with an evangelical denomination. Figure 6 shows substantial within-cohort change in frequent prayer until 2004: Most of the lines slope upward, suggesting that people tend to pray more often as they get older. After 2004, however, within-cohort change seems to stop, 


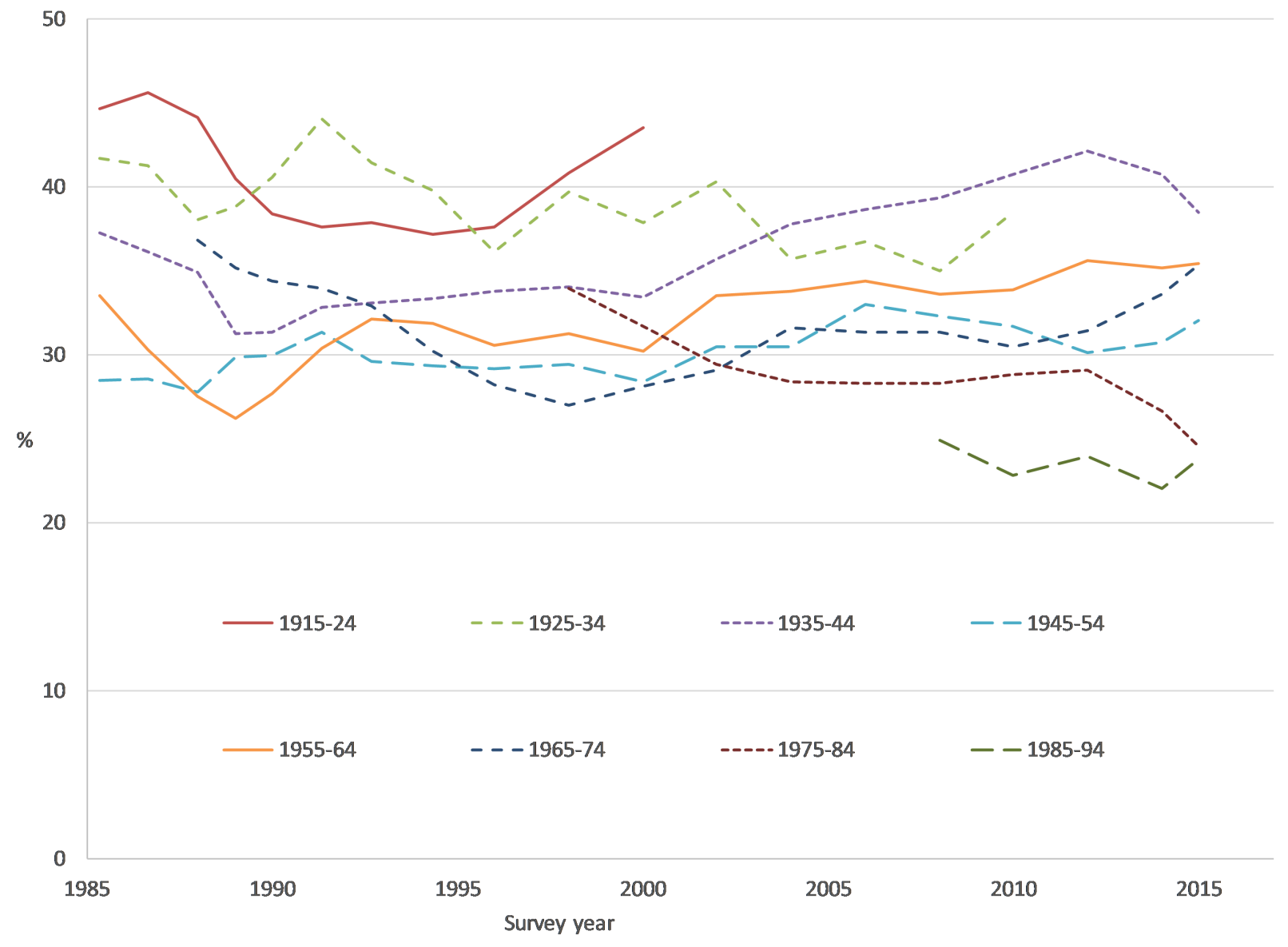

Figure 4: Says that "the Bible is the actual word of God and is to be taken literally, word for word" by decade of birth and survey year, 1984-2016. Source: GSS 1984-2016; graph shows a three-survey moving average.

whereas differences between cohorts remain. It appears that until a decade or so ago, people prayed more as they aged, with each successive cohort following a similar trajectory. But the situation seems to be different since 2004, when the same generation gaps appear for prayer as for the other indicators. Together with the observation noted earlier about the large jump in reported prayer between 2002 and 2004, this unusual pattern deserves further attention.

The other exception to the typical cohort pattern is identification with a denomination classified as evangelical. The various birth cohorts are not clearly differentiated prior to about 1990, and most of the within-cohort change is in a positive direction. Thereafter, the situation is similar to that for the other variables: Each successive cohort has lower values than the one before, and those values are relatively stable over time.

These exceptions notwithstanding, the cohort comparisons taken as a whole provide overwhelming evidence of intergenerational decline in intense religiosity. The differences between older and younger cohorts are being translated into an aggregate decline, but that process is slow and easy to miss if one examines only 


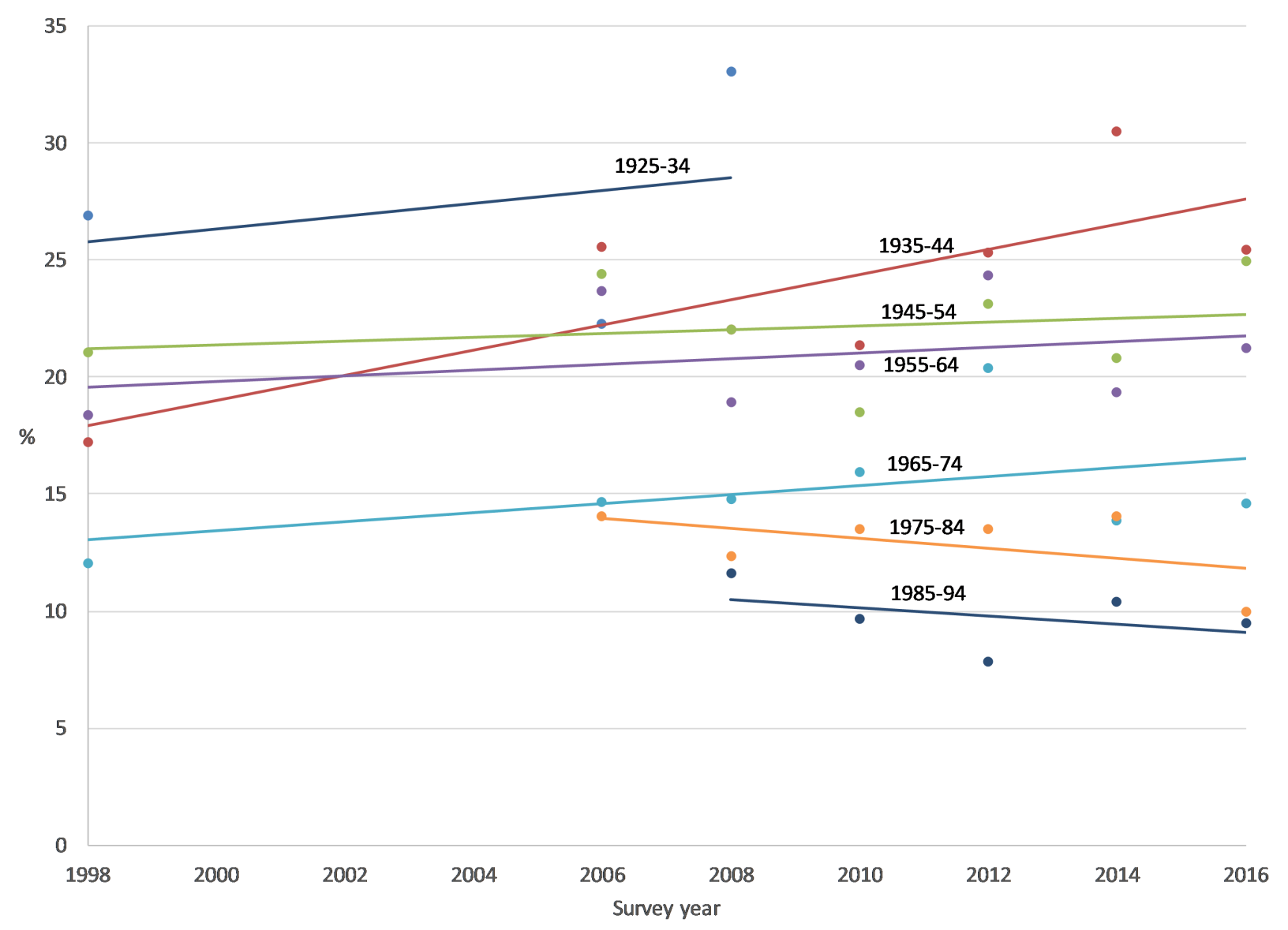

Figure 5: Describes self as "very religious" by decade of birth and survey year, 1998-2016. Source: GSS 1998-2016; only points based on 100+ cases are shown.

changes in population totals. Anyone wishing to argue that intense religiosity in the United States will persist at current levels is obliged to claim that religiosity rises steeply with age, something for which there is scant evidence. The aggregate change and the cohort evidence clearly point in the same direction: declining intense religiosity in the United States. ${ }^{19}$

\section{Conclusion}

Secularization came late to the United States. The country is highly religious compared to other Western nations, and more of its population is intensely religious. When Schnabel and Bock claim that "the intensity of American religion is persistent and exceptional," however, they are mistaken. Even intense religiosity has eroded in the United States in recent decades. They mistakenly concluded otherwise because their analytical strategy was not sufficiently sensitive to detect very slow change, they examined a limited set of indicators, and they paid insufficient attention to cohort differences. 


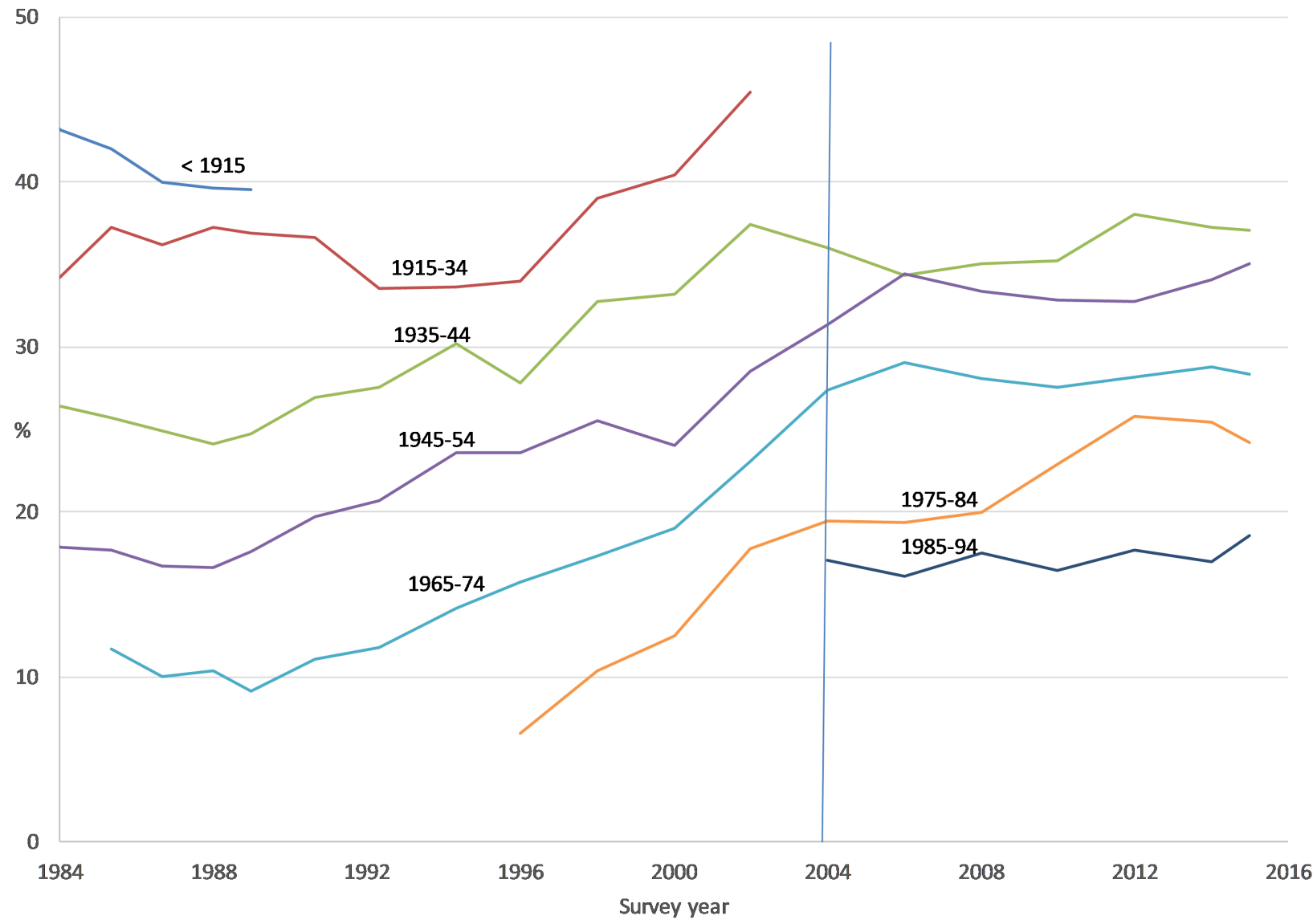

Figure 6: Prays several times per day (\%) by decade of birth and survey year, 1983-2016. Source: GSS 1983-2016; graph shows a three-survey moving average.

The intensely religious population may be declining more slowly than the more moderately religious population, but this is to be expected. Nominal members are the first to defect, doubters are the first to disbelieve, and occasional churchgoers are the first to stop attending; a committed core remains. Societies become more secular not because no one is highly religious but because diversity in religiosity increases (Wilkins-Laflamme 2014, 2016a, 2016b).

It would not be correct to conclude, however, that intense religiosity is holding up much better than moderate religiosity. The indicators of strong affiliation, frequent attendance at services, and firm belief all show appreciable decline in aggregate and very substantial differences between young and old cohorts. Change is slow, as is usually the case when it is driven by generational replacement, but that is true for moderate religion as well. And in proportional terms, the declines in moderate religiosity are similar in magnitude to the declines in more-than-weekly attendance at services (from 8.1 percent in 1973 through 1978 to 6.6 percent in 2010 through 2016) or biblical literalism (from 37.3 percent in 1984 through 1987 to 30.7 percent in 2012 through 2016). The erosion of intense religiosity is less obvious than 
for nominal religiosity in part because it is harder to spot a decline in values that are already low.

The question is whether the highly religious can successfully resist the force of social change because America is somehow exceptional. The evidence leads us to doubt it. America is not immune to religious decline; moreover, it is not exceptional in the proximate cause of that decline, which is generational replacement. The argument for American religious exceptionalism posits a peculiar resistance to forces that have undermined religion in other modern societies. We doubt that the United States is impervious to that sort of social change.

This is not the place to repeat our full argument about why the United States should no longer be considered an exception to the secularization thesis. We encourage interested readers to consult our original article. Suffice it to say here that our basic point was that America is not a counterexample to the secularization thesis because religious affiliation, belief, and practice in the United States have in fact been declining for decades and because this decline has been produced by the same generational patterns underlying religious decline elsewhere in the West: Each successive cohort is less religious than the preceding one. The present article shows that these claims apply to intense as well as moderate religiosity. The change is slow but unmistakable. Intense religiosity in the United States is neither persistent nor exceptional in ways that constitute a counterexample to the secularization thesis.

\section{Notes}

1 Respondents were only asked whether they were born in the United States from 1977 onward. For earlier years, and when there are missing values on the nativity question, we treat being a resident in the country at age 16 years as a proxy. We estimate that less than 2 percent of resident-at-16 respondents for the years 1973 through 1976 would have been born abroad. See Voas and Chaves (2016:1529-30,1546-7) for an extended rationale for limiting the analysis to the native-born population.

2 Schnabel and Bock say that they "focus on the time period from the end of the 1980s to today, during which disaffiliation has been occurring more rapidly" (2017:688). We do not think this is a good reason to limit attention to these years. The prayer and literalism trends in Figure 1 begin later than 1973 because the GSS first asked these questions in 1983 and 1984, respectively. We exclude the unusually religious 1972 GSS sample to avoid overstating religious decline.

3 In 2004, a question on images of the world and human nature was dropped from the sequence of items on religion; a question on images of God had been dropped earlier. In consequence, respondents were taken straight from a question about life after death to the question about prayer, and it is possible that they were thereby primed to give a more religious response to the prayer question than had been the case previously.

4 Surveys carried out by the Pew Research Center also show a decline in daily prayer from 2002 to 2007 and then to 2014; see http: / / www.pewforum.org/religious-landscapestudy/frequency-of-prayer/ and also http:/ / www.thearda.com/QuickStats/qs_104_s.asp.

5 Attendance multiple times per week was greater than 7 percent for every survey between 1973 and 1988. Since 2010, the value has always been less than 7 percent.

6 Consistent with the curvilinearity and discontinuity that we discussed above, the evangelical share of the population and the percentage of those saying that they pray 
several times per day also declined significantly in the most recent decades when we aggregate the surveys starting in 1989 for evangelical affiliation (31.0 percent in the pooled 1989-1994 surveys) and starting in 2004 for frequent praying (30.1 percent in the pooled 2004-2008 surveys).

7 The other options are "I don't believe in God"; "I don't know whether there is a God, and I don't believe there is a way to find out"; "I don't believe in a personal God, but I do believe in a Higher Power of some kind"; "I find myself believing in God some of the time, but not at others"; and "While I have doubts, I feel that I do believe in God."

8 This question was first asked in 1998 and then not again until 2006.

9 This question was asked only in 1988, 2006, 2008, and 2010.

10 This question was asked only in 1998, 2006, 2008, and 2010.

11 We would have liked to include considering oneself very religious in this measure, but this question was first asked only in 1998, and we wanted a measure that allowed us to start observing earlier than that.

12 There might also be confounding period effects, but any plausible scenario would involve higher levels of intense religiosity in the past than in the present.

13 Since 1988, "only [one-fifth] of the impact of cohort replacement [on having a strong religious identity] is offset by positive within-cohort change. The very slight upward drift within cohorts may represent a consolidation of religious identity with age" (Voas and Chaves 2016:1543).

14 See Voas and Chaves (2016:1527-9) for why a graphical approach is appropriate and more elaborate statistical strategies for disentangling age, period, and cohort effects are unhelpful in this instance.

15 See Voas and Chaves (2016:1544-6) for more details.

16 All of these graphs are available from the authors upon request.

17 A curiosity here is that in most years, older baby boomers (born 1945-1954) are a little less likely to be biblical literalists than younger baby boomers (born 1955-1964).

18 See Kim, Smith, and Kang (2015) for a recent examination of the well-established link between religious service attendance and reduced mortality.

19 We have focused on evidence from the GSS, but surveys conducted by the Pew Research Center in 2007 and again in 2014 also show a decline in the proportion of people choosing the most religious answers to questions they asked, including believing in God with absolute certainty, saying religion is "very important" in their lives, attending services at least weekly, believing that scripture should be taken literally, and (as mentioned earlier) saying they pray at least daily (http:/ / www.pewforum.org/religious-landscapestudy/).

\section{References}

Chaves, Mark. 2017. American Religion: Contemporary Trends. 2nd ed. Princeton, NJ: Princeton University Press.

Hout, Michael, and Claude S. Fischer. 2014. "Explaining Why More Americans Have No Religious Preference: Political Backlash and Generational Succession, 1987-2012." Sociological Science 1:423-47. https ://doi .org/10.15195/v1.a24.

Kim, Jibum, Tom W. Smith, and Jeong-han Kang. 2015. "Religious Affiliation, Religious Service Attendance, and Mortality." Journal of Religion and Health 54:2052-72. https : //doi.org/10.1007/s10943-014-9902-7. 
Kregting, Joris, Peer Scheepers, Paul Vermeer, and Chris Hermans. 2018. "Why God Has Left the Netherlands: Explanations for the Decline of Institutional Christianity in the Netherlands Between 1966 and 2015." Journal for the Scientific Study of Religion 57:58-79. https://doi.org/10.1111/jssr.12499.

Molteni, Francesco, and Ferruccio Biolcati. 2018. "Shifts in Religiosity across Cohorts in Europe: A Multilevel and Multidimensional Analysis Based on the European Values Study." Social Compass 65:413-32. https://doi .org/10.1177/0037768618772969.

Putnam, Robert D., and David E. Campbell. 2010. American Grace: How Religion Divides and Unites Us. New York, NY: Simon \& Schuster.

Ruck, Damian J., R. Alexander Bentley, and Daniel J. Lawson. 2018. “Religious Change Preceded Economic Change in the 20th Century." Scientific Advances 4:eaar8680.

Schnabel, Landon, and Sean Bock. 2017. "The Persistent and Exceptional Intensity of American Religion: A Response to Recent Research." Sociological Science 4:686-700. https://doi.org/10.15195/v4.a28.

Steensland, Brian, Jerry Z. Park, Mark D. Regnerus, Lynn D. Robinson, W. Bradford Wilcox, and Robert D. Woodberry. 2000. "The Measure of American Religion: Toward Improving the State of the Art." Social Forces 79:291-318. https://doi .org/10.1093/sf/79.1.291.

Voas, David, and Mark Chaves. 2016. "Is the United States a Counterexample to the Secularization Thesis?" American Journal of Sociology 121:1517-56.

Wilkins-Laflamme, Sarah. 2014. “Towards Religious Polarization? Time Effects on Religious Commitment in US, UK and Canadian Regions." Sociology of Religion 75:284-308. https : //doi.org/10.1093/socrel/sru001.

Wilkins-Laflamme, Sarah. 2016a. "Secularization and the Wider Gap in Values and Personal Religiosity between the Religious and Non-Religious." Journal for the Scientific Study of Religion 55:717-36. https://doi.org/10.1111/jssr.12307.

Wilkins-Laflamme, Sarah. 2016b. "The Remaining Core: A Fresh Look at Religiosity Trends in Great Britain." British Journal of Sociology 67:632-54. https://doi.org/10.1111/ $1468-4446.12205$.

Acknowledgments: David Voas received funding from the U.K. Economic and Social Research Council via the Research Centre on Micro-Social Change. The authors thank Tom Smith for helping to detail the changes that occurred in the General Social Survey between 2002 and 2004 and Simon Brauer for suggesting the use of a scale measure of intense religiosity.

David Voas: Department of Social Science, University College London. E-mail: d.voas@ucl.ac.uk.

Mark Chaves: Department of Sociology, Duke University. E-mail: mac58@soc.duke.edu. 